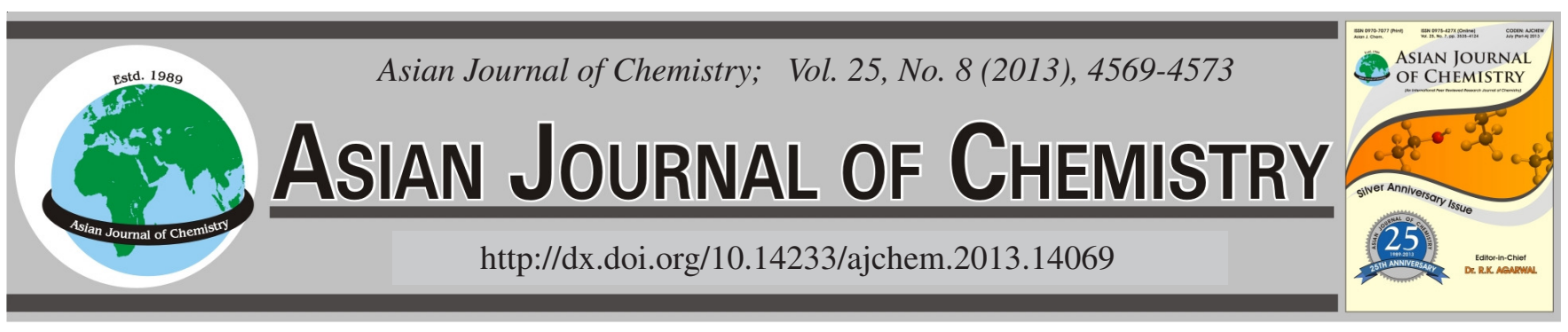

\title{
Effects of Different Relative Humidities on the Corrosion of the Epoxy-Coated Galvanized Steel in the Presence of Sulfur Dioxide
}

\author{
REsIT YILDIZ and ILYAS DEHRI*
}

Department of Chemistry, Cukurova University, 01330 Adana, Turkey

*Corresponding author: Fax: +90 322 3386070; Tel: +90 322 3386084-2465; E-mail: idehri@cu.edu.tr; ryildiz80@gmail.com

The effects of sulfur dioxide on the atmospheric corrosion of epoxy-coated galvanized steels exposed to different relative humidity was investigated using electrochemical impedance spectroscopy, anodic polarization curves and linear polarization resistance measurement techniques. Measurements were performed on samples that had been tested using an accelerated atmospheric corrosion test. The samples were exposed to sulfur dioxide gas in an atmospheric corrosion test cell that was adjusted to different relative humidities. The results indicate that the coating performance varies with relative humidity. Epoxy-coated samples exposed to relative humidities of 70 and $80 \%$ experienced no degradation, whereas the samples significantly lost their protection behaviour under relative humidities of 90 and $100 \%$.

Key Words: Galvanized steel, Epoxy coatings, Relative humidity, $\mathrm{SO}_{2}$, Electrochemical impedance spectroscopy.

\section{INTRODUCTION}

Atmospheric corrosion is one of the most widespread forms of metallic corrosion, which occurs on a metallic surface that is covered with a thin layer of dilute electrolyte produced from condensation or adsorption. The corrosion behaviour of metals coated with a thin electrolyte layer differs from metals in bulk solutions. Atmospheric corrosion occurs mainly from the presence of salt and gases that are dissolved in a thin layer on the surface of a metal. The atmospheric corrosion rate for metals depends on the thickness of the electrolyte layer ${ }^{1}$. Changes in the thickness of the layer affect the gas transport rate of oxygen through the electrolyte layer and the solubility of the corrosion products and hence, the metal corrosion rates ${ }^{2}$.

Galvanized steels are increasingly being used in automobiles, building structures, roofing and other industrial structures because of their high corrosion resistance compared to iron. There are numerous literature reports on the investigation of the corrosion performance of galvanized steels ${ }^{3-8}$.

The presence of chemically active pollutants that are water soluble has a considerable effect on corrosion in humid atmospheres. Sulfur dioxide is the most widespread contaminant in the atmosphere in urban and industrial regions. Sulfur dioxide is dissolved in the moisture film and is primarily oxidized into sulphuric acid ${ }^{9}$. Thus, many corrosion product films formed in the atmosphere contain large concentrations of sulphate ions from species like sulphite and bisulphate ${ }^{10-12}$. Additionally, if the conditions are suitable, generally at high partial pressures of sulfur dioxide, sulfur dioxide may act as a cathodic reductant, which results in the formation of various reduced sulphur anions, e.g., thiosulphite, di-thionite, sulphite and sulphide ${ }^{13}$.

Organic coatings are the most commonly used method for the protection of metals from corrosion. Organic coatings have long been used for the protection of metals and alloys against corrosion. However, mechanical damage can remarkably decrease the protection properties, even in the case of protective organic coatings. Although such coatings form a barrier against the diffusion of aggressive ions, water and oxygen are permeable, therefore, they can be present at the metalcoating interface. Under certain circumstances, the presence of water and oxygen can lead to substrate corrosion and coating delamination ${ }^{14}$. The use of organically coated galvanized steel products in a wide variety of industrial applications has grown drastically, which has inevitably led to increasing performance demands. Therefore, it is vitally important, both from a commercial and an environmental perspective, to optimize the lifetime of products by minimizing degradation.

Electrochemical impedance spectroscopy has been used by a significant amount by other workers during the study of the general degradation of organic coatings ${ }^{15-24}$, the impedance response of organic coatings with artificially produced defects ${ }^{25}$ and the impedance response of painted galvanized steel.

In this work, the sulfur dioxide gas degradation of paint films on epoxy-coated galvanized steel substrates under different relative humidities were studied using electrochemical 
impedance spectroscopy (EIS), anodic polarization curves and linear polarization resistance (LPR) measurements. The data obtained from these tests were interpreted in terms of an equivalent electrical circuit and the components of the circuit were related to the electrochemical processes on the coated specimen.

\section{EXPERIMENTAL}

Sections of galvanized steels, with dimensions of $5 \mathrm{~cm} \times$ $10 \mathrm{~cm}$ were first coated with $10 \mu \mathrm{m}$ of wash primer (polyvinyl butyral) and then 35-40 $\mu$ m of epoxy paint was applied as a top coat. A test cell was prepared, with dimensions of $50 \mathrm{~cm} \times$ $75 \mathrm{~cm} \times 40 \mathrm{~cm}$ made from Plexiglass that contained the appropriate water-glycerol mixture ${ }^{11}$ to control the internal relative humidity at different values. After $24 \mathrm{~h}$, after reaching equilibrium, the samples were placed at an inclination of $45^{\circ}$ relative to the horizon (Fig. 1), then the samples were exposed to $\mathrm{SO}_{2}$, according to the $\mathrm{SO}_{2}$ gas environment for 20 days at room temperature $\left(25^{\circ} \mathrm{C}\right)$. The rate of $\mathrm{SO}_{2}$ gas flow through the chamber was 0.17 and $0.16 \mathrm{~g} \mathrm{~s}^{-1}$ for air, which was regulated through-out the exposures to maintain constant $\mathrm{SO}_{2}$ in the amount of $1.2 \mathrm{~g} / \mathrm{m}^{3}$ and air density of $1.45 \mathrm{~g} / \mathrm{m}^{3}$ in test cell. Epoxy-coated galvanized steels were removed from the atmospheric corrosion testing cell after they were under the influence of $\mathrm{SO}_{2}$ for 20 days in 100, 90, 80 and $70 \%$ relative humidity. Three electrode electrochemical cells were produced by gluing PVC cylinders $\left(2 \mathrm{~cm}\right.$ in diameter and $3.14 \mathrm{~cm}^{2}$ ) onto the substrates and filling with a solution of artificial acid rain $(\mathrm{pH} 3.5)$, which was obtained by dissolving the $\mathrm{SO}_{2}$ gas in corrosive media. The counter electrode was a platinum sheet with a 1 $\mathrm{cm}^{2}$ surface area. $\mathrm{A} \mathrm{Ag} / \mathrm{AgCl}(3 \mathrm{M} \mathrm{KCl})$ electrode was used as the reference during the electrochemical measurements (Fig. 2). The polarization curves, electrochemical impedance spectroscopy and linear polarization resistance measurements were performed using a CHI 660 C Serial number: F1070. The epoxy-coated galvanized steel was immersed into corrosive media for $1 \mathrm{~h}$ to establish a steady state open circuit potential $\left(\mathrm{E}_{\mathrm{ocp}}\right)$. The electrochemical measurements were performed after measuring the $\mathrm{E}_{\text {ocp}}$. The EIS experiments were conducted in the frequency range of $100 \mathrm{kHz}$ to $10 \mathrm{mHz}$ at open circuit potential. The amplitude was $0.01 \mathrm{~V}$ (peak to peak). The LPR measurements were conducted by recording the electrode potential $\pm 0.010 \mathrm{~V}$ around the open circuit potential with a $0.001 \mathrm{~V} \mathrm{~s}^{-1}$ scan rate. The corrosion behaviour of the epoxy-coated galvanized steel in an artificial acid rain solution was also investigated as a function of the relative humidity with the polarization curves. The polarization curves were obtained in the potential ranges from $\left(\mathrm{E}_{\text {ocp }}\right)$ to $1.2 \mathrm{~V}$, with a scan rate of $0.001 \mathrm{~V} \mathrm{~s}^{-1}$.

\section{RESULTS AND DISCUSSION}

The Nyquist diagrams of the electrochemical impedance data for the sample that was exposed to $\mathrm{SO}_{2}$ gas for 20 days at $70,80,90$ and $100 \%$ relative humidities $(\mathrm{RH})$ are shown in Figs. 3-6, respectively.

The equivalent electrical circuits, which are proposed for the epoxy-coated galvanized steel specimens that were tested during the present study, are shown in Fig. 7(a-b). These

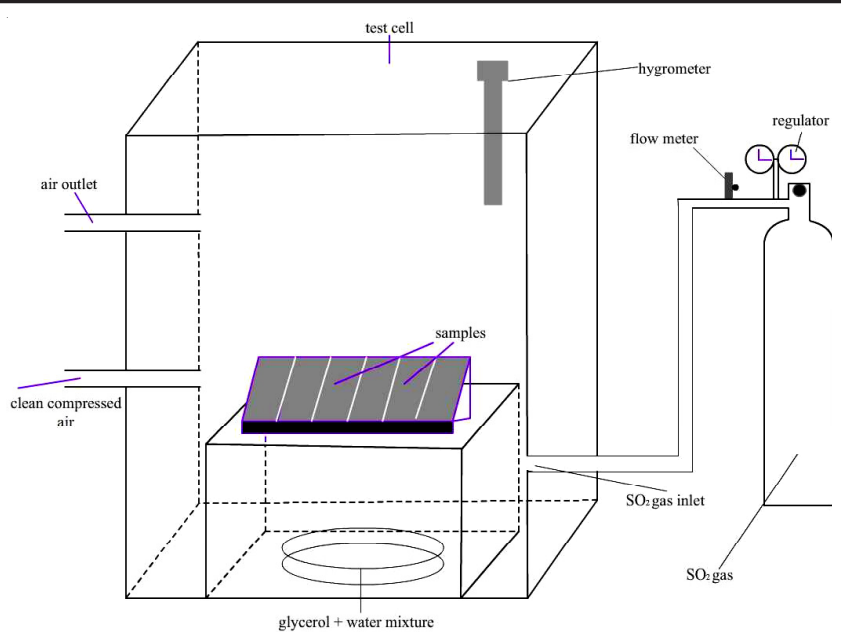

Fig. 1. Experimental test cell set-up

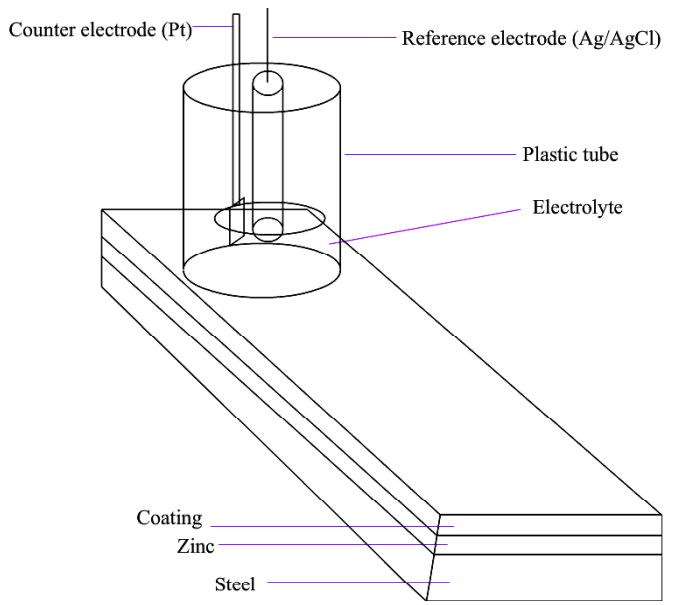

Fig. 2. Three-electrode system used for the impedance measurements on coated galvanized steel

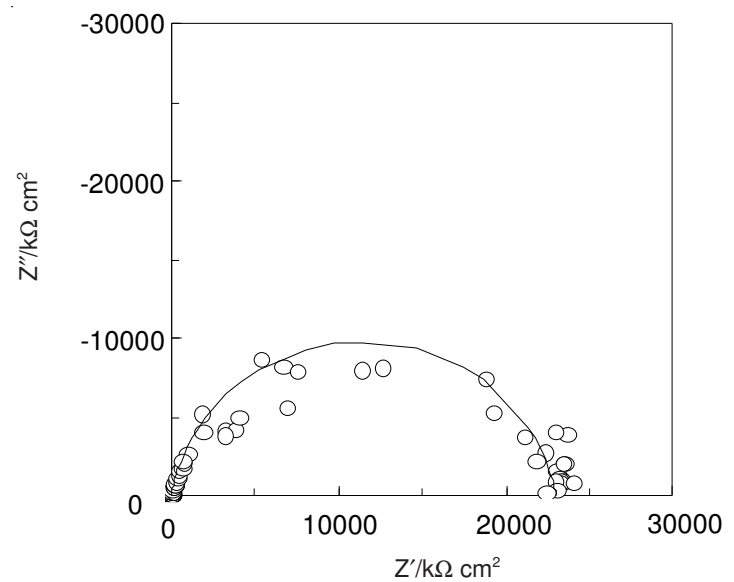

Fig. 3. Nyquist diagram of the epoxy-coated galvanized steel after being exposed to $\mathrm{SO}_{2}$ gas corrosion test for 20 days (o) at a relative humidity of $70 \%$. The fitted curve is shown as a solid line

circuits, with appropriate values for each circuit element, provided good simulations of the experimental data when the impedance of the constant phase element term is used instead of the double-layer capacitance and paint film capacitance.

The Nyquist plots show one capacitive arc and one time constant at 70 and $80 \%$ relative humidities (Figs. 3 and 4) The circuit in Fig. 7(a), with one time constant, appears to be 


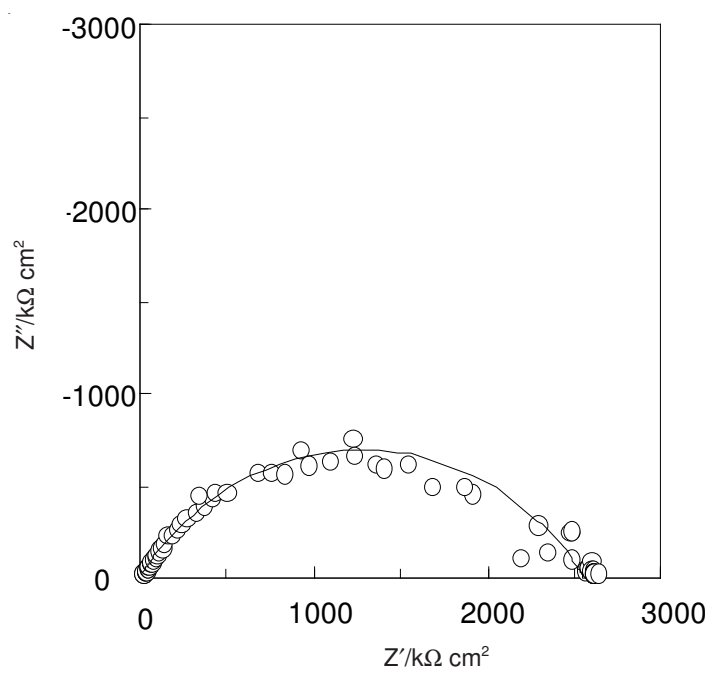

Fig. 4. Nyquist diagram of the epoxy-coated galvanized steel after being exposed to a $\mathrm{SO}_{2}$ gas corrosion test for 20 days (o) at a relative humidity of $80 \%$. The fitted curve is shown as a solid line

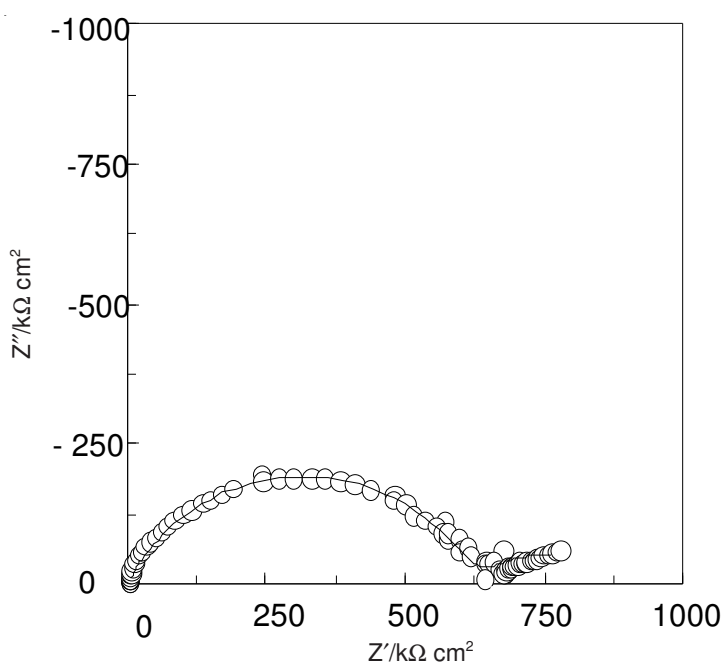

Fig. 5. Nyquist diagram of the epoxy-coated galvanized steel after being exposed to a $\mathrm{SO}_{2}$ gas corrosion test for 20 days (o) at a relative humidity of $90 \%$. The fitted curve is shown as a solid line

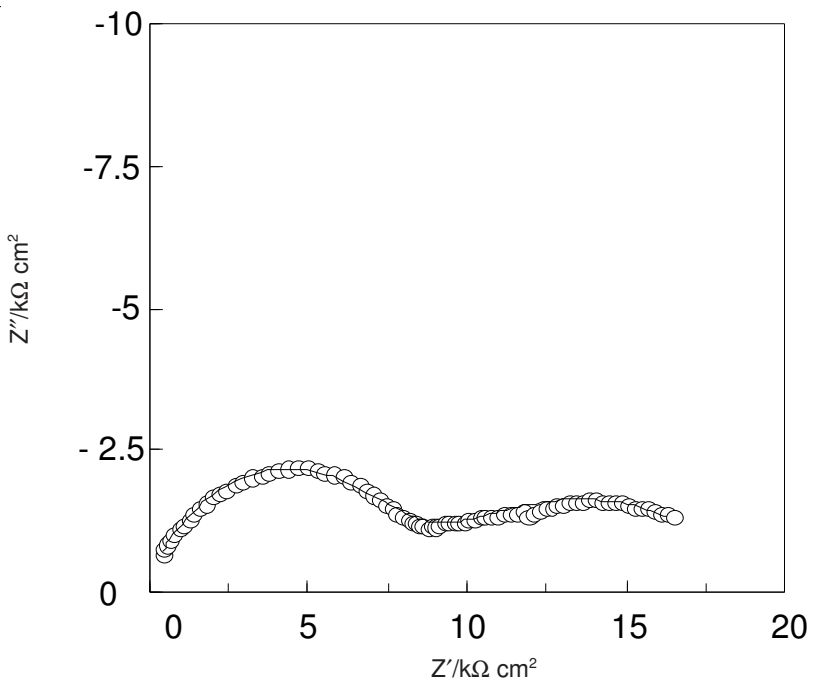

Fig. 6. Nyquist diagram of the epoxy-coated galvanized steel after being exposed to a $\mathrm{SO}_{2}$ gas corrosion test for 20 days (o) at a relative humidity of $100 \%$. The fitted curve is shown as a solid line the most suitable simulation for these relative humidities. Under these relative humidities, the coating resistance is too high in places where the organic coating is generally intact, but the coating resistance and capacitance are measurable. In this model, the single time constant represents the impedance of a surface coating or layer and can be described by coating capacitance $(C P E 1)$, solution resistance $\left(R_{s}\right)$ and coating resistance $\left(R_{p f}\right)^{26-30}$. The impedance parameters that were obtained by fitting the EIS data to the equivalent circuit are listed in Table- 1 . The calculated $\mathrm{R}_{\mathrm{pf}}$ values from the fitted impedance diagrams are 20954 and $2563 \mathrm{k} \Omega \mathrm{cm}^{2}$ at 70 and $80 \%$ relative humidities, respectively. The $* \mathrm{R}_{\mathrm{p}}$ value, also calculated from the LPR technique, is provided in Table-1. The $* \mathrm{R}_{\mathrm{p}}$ values, which were obtained from the LPR technique, are 31400 and $3140 \mathrm{k} \Omega \mathrm{cm}^{2}$ at the same $\mathrm{RH}$, respectively. When the relative humidity increases from 70-80\%, the resistance of epoxy coatings decreases approximately 8 times. Despite this, the protection of the metal has not been significantly lost.
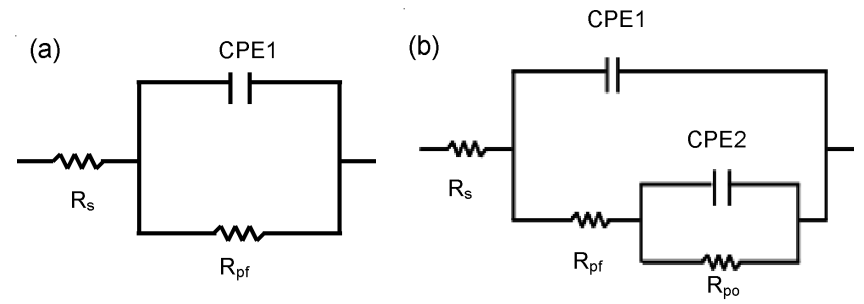

Fig. 7. Equivalent electrical circuit for defective organic-coated metals. (a) $R_{s}$ : solution resistance, $R_{p f}$ : coating resistance, CEP1: coating capacitance, (b) $\mathrm{R}_{\mathrm{po}}$ : pore resistance, $\mathrm{CPE} 2$ : double layer capacitance

It is apparent from Table- 1 that the constant phase element $(\mathrm{CPE})$ values tend to increase as the $\mathrm{R}_{\mathrm{pf}}$ value decreases. This decrease in the CPE can be attributed to the decrease of the local dielectric constant or to an increase in the thickness of the electrical double layer ${ }^{24,31}$.

Nyquist plots of the epoxy-coated galvanized steel sample that was exposed to $\mathrm{SO}_{2}$ gas for 20 days at $90 \% \mathrm{RH}$ are provided in Fig. 5. There are two capacitive loops observed in the high and low frequency regions. The high frequency capacitive loop is related to the coating resistance $\left(\mathrm{R}_{\mathrm{pf}}\right)$ and the low frequency capacitive loop is related to the pore resistance $\left(\mathrm{R}_{\mathrm{po}}\right)^{32,33}$.

The related electrochemical equivalent circuit that was used to model the epoxy-coated galvanized steel/electrolyte solution interface is shown in Fig. 7(b), where $R_{s}$ represents the solution resistance, the $\mathrm{R}_{\mathrm{pf}}$, which corresponds to the first loop of Nyquists plot and $R_{p o}$ represents the pore resistance. $\mathrm{R}_{\mathrm{po}}\left(\mathrm{R}_{\mathrm{po}}=\mathrm{R}_{\mathrm{ct}}+\mathrm{R}_{\mathrm{d}}+\mathrm{R}_{\mathrm{a}}\right)$ and it includes the charge transfer resistance $\left(R_{c t}\right)$, diffuse layer resistance $\left(R_{d}\right)$ and the accumulated species resistance at the metal/solution interface $\left(R_{a}\right)$. $* \mathrm{R}_{\mathrm{p}}$ represents the polarization resistance. The value of $\mathrm{n}$ is between 0 and $1(0 \leq n \leq 1)$ which is related to the deviation from the ideal capacitive behaviour ${ }^{34}$. The CPE represents a constant phase element to replace the double-layer capacitance $\left(\mathrm{C}_{\mathrm{dl}}\right)$ to provide a more accurate fit to the experimental results ${ }^{35}$. The impedance parameters that were obtained by fitting the EIS data to the equivalent circuit are listed in Table-1. In Table1, CPE1 and CPE2 represent the coating capacitance and double layer capacitance, respectively. The total capacitance 
TABLE-1

FITTING PARAMETERS CPE1, $R_{\mathrm{p}}$, CPE2, $\mathrm{R}_{\mathrm{po}}$ AND $\mathrm{n}$ FOR THE EPOXY COATING AT 70-100 \% RELATIVE HUMIDITY

\begin{tabular}{cccccccc} 
Relative humidity $(\%)$ & $(\mathrm{LPR}) * \mathrm{R}_{\mathrm{P}}\left(\mathrm{k} \Omega \mathrm{cm}^{2}\right)$ & $\mathrm{R}_{\mathrm{pf}}\left(\mathrm{k} \Omega \mathrm{cm}^{2}\right)$ & $\mathrm{R}_{\mathrm{po}}\left(\mathrm{k} \Omega \mathrm{cm}^{2}\right)$ & $\mathrm{CPE} 1\left(\mathrm{~F} \mathrm{~cm}^{-2}\right)$ & $\left.\mathrm{CPE} 2(\mathrm{~F} \mathrm{~cm})^{-2}\right)$ & $\mathrm{n}_{1}$ & $\mathrm{n}_{2}$ \\
\hline 70 & 31400 & 20954 & - & $1.82 \times 10^{-9}$ & - & 0.89 & - \\
80 & 3140 & 2563 & - & $5.19 \times 10^{-9}$ & - & 0.65 \\
90 & 785 & 628 & 251 & $9.49 \times 10^{-9}$ & $1.28 \times 10^{-5}$ & 0.70 & 0.50 \\
100 & 16 & 8.4 & 9.5 & $4.70 \times 10^{-7}$ & $8.99 \times 10^{-5}$ & 0.58 & 0.45
\end{tabular}

of the capacitors is equal to the sum of the double-layer and coating capacitances. During the evaluation of Table-1, the calculated $R_{\mathrm{pf}}$ value is $628 \mathrm{k} \Omega \mathrm{cm}^{2}$ for 20 days, which indicates more corrosion processes.

In Fig. 6, the Nyquist plot for the epoxy-coated galvanized steel sample exposed to $\mathrm{SO}_{2}$ gas for 20 days at $100 \%$ relative humidity is given. As seen in Fig. 6, there are two time constants. The high frequency capacitive loop is related to the coating resistance $\left(\mathrm{R}_{\mathrm{pf}}\right)$. The low frequency capacitive loop is related to the pore resistance $\left(\mathrm{R}_{\mathrm{po}}\right)^{36-38}$. The Nyquist plots of the epoxycoated galvanized steel in $\mathrm{SO}_{2}$ gas at $100 \%$ relative humidity do not yield the perfect semicircle that is generally attributed to the frequency dispersion, as well as to the inhomogeneity of the surface and resistance to mass transport. A slightly depressed semi-circular shape in the Nyquist plot indicates that the corrosion of the epoxy-coated galvanized steel is primarily controlled through a charge transfer process ${ }^{36}$. It is known that the anodic dissolution of epoxy-coated galvanized steel and the cathodic oxygen reduction reactions occur simultaneously on the metal surface. The diffusion process may either be due to the transportation of corrosive ions and soluble corrosion products at the metal/solution interface or to the diffusion of dissolved oxygen to the surface of the coated galvanized steel ${ }^{39}$. However, the latter is more probable. The values of the resistance and capacitance, as determined from the Nyquist plots for the equivalent circuit, are given in Table1. It is evidenced in Table- 1 that the calculated film resistance of the epoxy-coated galvanized steel reduced to $8.4 \mathrm{k} \Omega \mathrm{cm}^{2}$ at $100 \% \mathrm{RH}$. The $\mathrm{R}_{\mathrm{p}}\left(* \mathrm{R}_{\mathrm{p}}\right)$ values, also calculated from the LPR technique, are given Table-1. The LPR technique was used for $\mathrm{R}_{\mathrm{p}}$, which is more or less confirmed the EIS results.

After accelerated corrosion tests two types of coated areas were distinguished, specifically, the areas of intact coating at 70 and $80 \% \mathrm{RH}$ and the areas of defective coating at 90 and $100 \% \mathrm{RH}$, where the corrosion occurs. The former produce impedance plots that have a single time constant and the latter have two-time constants. These two types of areas represent stages on the continuum of coating degradation ${ }^{14}$. The $\mathrm{R}_{\mathrm{pf}}$ value was less than $150 \mathrm{k} \Omega \mathrm{cm}^{2}$ only at $100 \% \mathrm{RH}$. $\mathrm{R}_{\mathrm{pf}}$ is only 8.4 $\mathrm{k} \Omega \mathrm{cm}^{2}$. This means that the epoxy coating was undamaged under 70 and $80 \%$ RH. It was degraded at 90 and $100 \% \mathrm{RH}$ in the presence of coating defects that facilitate corrosion under the film. Furthermore, because the values for $\mathrm{n}$ are small for these relative humidities, a diffusional or dispersive impedance response is dominant. The diffusional impedance may arise from the barrier preventing metal ion movement outwards or oxygen diffusion inwards, which is provided by corrosion products on the corroding metal surface. This diffusional control modifies the impedance response of the corroion reaction, e.g., the charge transfer resistance and double layer capacitance.
The representative anodic polarization curves of the epoxy-coated galvanized steel that was exposed to $\mathrm{SO}_{2}$ gas for 20 days at different relative humidities (70, 80, 90 and 100 $\%)$ are shown in Fig. 8.

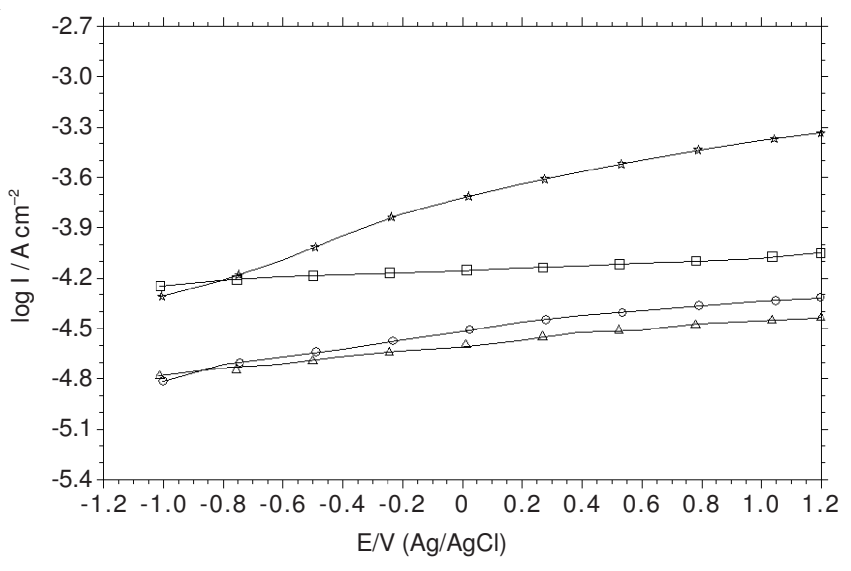

Fig. 8. Anodic polarization curves of epoxy-coated galvanized steels after exposure to a $\mathrm{SO}_{2}$ gas for 20 days at relative humidities of $70 \%$ $(\triangle), 80 \%($ o), $90 \%(\square)$ and $100 \%(*)$

As clearly seen in Fig. 8, an increase in the anodic dissolution of metal would be expected with increasing relative humidities. The corrosion current density, as well as the corrosion rate of the coating, increased considerably with humidity. These results are indicative of the presence of some defects with the corrosion process on the coating. The anodic current-potential curves (Fig. 8), which give rise to parallel lines, indicate that the change in relative humidity does not modify the anodic dissolution mechanism of the metal. However, there is not an absolute shift in the corrosion potential to either more anodic or more cathodic potentials in response to different relative humidities. These results indicate that the corrosion current density depends on the humidity. The current density increased slightly when the relative humidity changed from $70-90 \%$. The current density was further increased after the relative humidity was increased to $100 \%$.

\section{Conclusion}

The effect of sulfur dioxide on the atmospheric corrosion of epoxy-coated galvanized steel at different relative humidity was studied using electrochemical impedance spectroscopy, linear polarization resistance and current-potential measurements. From the obtained results, the following points can be emphasized: After exposure to $\mathrm{SO}_{2}$ gas for 20 days in a test cell, the epoxy-coated specimens experienced corrosion and the corrosion process is confirmed through localized impedance measurements. Epoxy-coated galvanized steel provides effective protection from corrosion under lower relative humidity (less than $90 \% \mathrm{RH}$ ) atmospheric conditions with $\mathrm{SO}_{2}$ gas. 
The experimental data were fitted using the ZView program and appropriate values for each equivalent circuit element have been identified for epoxy-coated galvanized steel after exposure to $\mathrm{SO}_{2}$ gas in atmospheric corrosion tests. According to the EIS results, the resistance of the epoxy-coated galvanized steel was observed to decrease more under $100 \%$ relative humidity. When the relative humidities were changed from $70-100 \%$, the radius of the semicircle decreased. This was confirmed with linear polarization resistance method. As shown in the Tafel curves, the current density values were increased with increasing relative humidity. Atmospheric conditions with higher relative humidity and $\mathrm{SO}_{2}$ gas accelerated the damage and corrosion rate of the epoxy-coated galvanized steel.

\section{ACKNOWLEDGEMENTS}

This study was supported by Cukurova University Research Found (FEF2010D10).

\section{REFERENCES}

1. N.D. Tomashow, Corrosion, 20, 76 (1964).

2. A. Nishikata, Y. Ichihara and T. Tsuru, Corros. Sci., 37, 897 (1995).

3. A.P. Yadav, A. Nishikata and T. Tsuru, Corros. Sci., 46, 169 (2004).

4. A.P. Yadav, A. Nishikata and T. Tsuru, Corros. Sci., 46, 361 (2004).

5. K. Videm and R. Myrdal, The Electrochemical Behaviour of Steel in Concrete and How to Evalute the Corrosion Rate, National Association of Corrosion Engineers, Corrosion 96 Paper No. 348 (1996).

6. C.E. Bird, Mater. Perform., 16, 14 (1977).

7. T.E. Graedal, J. Electrochem. Soc., 136, 193 (1989).

8. A.P. Yadav, H. Katayama, K. Noda, H. Masuda, A. Nishikata and T. Tsuru, Corros. Sci., 49, 3716 (2007).

9. J.C. Scully, International Series on Materials Science and Technology, The Fundamentals of Corrosion, edn. 2, Vol. 17 (1975).

10. T.K. Ross, Engineering Design Guides 21, Metal Corrosion, Published fort he Design Council, The British Standards Institution and the Council of Engineering Institutions by Oxford University Press, Oxford (1977).

11. I. Dehri, B. Yazici, M. Erbil and H. Galip, Corros. Sci., 36, 2181 (1994).

12. S. Beilke and G. Gravenhorst, Atmos. Environ., 12, 231 (1978).
13. J.W. Moore and E.A. Moore, Environmental Chemistry, Acedemic Press, New York (1976).

14. I. Dehri, R.L. Howard and S.B. Lyon, Corros. Sci., 41, 141 (1999).

15. F. Mansfeld and C.H. Tsai, Corrosion, 47, 958 (1991).

16. C. Li, Y. Ma, Y. Li and F. Wang, Corros. Sci., 52, 3677 (2010).

17. M. Niknahad, S. Moradian and S.M. Mirabedini, Corros. Sci., 52, 1948 (2010).

18. G.A. El-Mahdy, Atsushi, Nishikata and T. Tsuru, Corros. Sci., 42, 1509 (2000).

19. D. Santos, C. Brites, M.R. Costa and M.T. Santos, Prog. Org. Coat., 54, 344 (2005)

20. I.M. Zin, S.B. Lyon and A. Hussain, Prog. Org. Coat., 52, 126 (2005).

21. Y. Gonzalez-Garcia, S. Gonzalez and R.M. Souto, Corros. Sci., 49, 3517 (2007).

22. F. Deflorian, S. Rossi, L. Fedizzi and P.L. Bonora, Prog. Org. Coat., 52, 271 (2005).

23. D.J. Penney, J.H. Sullivan and D.A. Worsley, Corros. Sci., 49, 1321 (2007).

24. S. Rossi, F. Deflorian, L. Fontanari, A. Cambruzzi and P.L. Bonora, Prog. Org. Coat., 52, 288 (2005).

25. F.M. Geenen, J.H.W. de Wit and E.P.M. van Westing, Prog. Org. Coat., 18, 299 (1990).

26. M. Hattori, A. Nishikata and T. Tsuru, Corros. Sci., 52, 2080 (2010).

27. I. Dehri, H. Sözüsaglam and M. Erbil, Prog. Org. Coat., 48, 118 (2003).

28. B. Nikravesh, B. Ramezanzadeh, A.A. Sarabi and S.M. Kasiriha, Corros. Sci., 53, 1592 (2011).

29. Y. Zhu, J. Xiong, Y. Tang and Y. Zuo, Prog. Org. Coat., 69, 7 (2010).

30. M. Marti, G. Fabregat, D.S. Azambuja, C. Aleman and E. Armelin, Prog. Org. Coat., 73, 321 (2012).

31. A.C. Bastos and A.M.P. Simoes, Prog. Org. Coat., 65, 295 (2009).

32. I. Dehri and M. Erbil, Corros. Sci., 42, 969 (2000).

33. I. Thompson and D. Campbeel, Corros. Sci., 36, 187 (1994).

34. J.T. Zhang, J.-M. Hu, J.-Q. Zhang and C.-N. Cao, Prog. Org. Coat., 51, 145 (2004).

35. V. Lavaert, M. Moors and E. Wettinck, J. Appl. Electrochem., 32, 853 (2002).

36. I.M. Zin, R.L. Howard, S.J. Badger, J.D. Scantlebury and S.B. Lyon, Prog. Org. Coat., 33, 203 (1998).

37. P.L. Bonora, F. Deflorain and L. Fedrizzi, Electrochim. Acta, 41, 1073 (1996).

38. M. Özcan, I. Dehri and M. Erbil, Prog. Org. Coat., 44, 279 (2002).

39. D.A. Worsley, D. Williams and J.S.G. Ling, Corros. Sci., 43, 2335 (2001). 